\title{
Addressing Social Determinants of Health in a Clinic Setting: The WellRx Pilot in Albuquerque, New Mexico
}

\author{
Janet Page-Reeves, PhD, Will Kaufman, MD, MPH, Molly Bleecker, MA, \\ Jeffrey Norris, MD, Kate McCalmont, MD, Veneta Ianakieva, MD, \\ Dessislava Ianakieva, MD, and Arthur Kaufman, MD
}

\begin{abstract}
Although it is known that the social determinants of health have a larger influence on health outcomes than health care, there currently is no structured way for primary care providers to identify and address nonmedical social needs experienced by patients seen in a clinic setting. We developed and piloted WellRx, an 11-question instrument used to screen 3048 patients for social determinants in 3 family medicine clinics over a 90-day period. Results showed that $46 \%$ of patients screened positive for at least 1 area of social need, and $63 \%$ of those had multiple needs. Most of these needs were previously unknown to the clinicians. Medical assistants and community health workers then offered to connect patients with appropriate services and resources to address the identified needs. The WellRx pilot demonstrated that it is feasible for a clinic to implement such an assessment system, that the assessment can reveal important information, and that having information about patients' social needs improves provider ease of practice. Demonstrated feasibility and favorable outcomes led to institutionalization of the WellRx process at a university teaching hospital and influenced the state department of health to require managed care organizations to have community health workers available to care for Medicaid patients. (J Am Board Fam Med 2016;29: 414-418.)
\end{abstract}

Keywords: Clinical Medicine, Primary Health Care, Social Determinants of Health, Social Problems

Physicians recognize that a patient's socioeconomic circumstances have a significant effect on health. ${ }^{1}$ As highlighted in the 2011 report "Health Care's

This article was externally peer reviewed.

Submitted 26 August 2015; revised 16 November 2015; accepted 17 November 2015.

From the Department of Family \& Community Medicine, University of New Mexico, Albuquerque (JP-R, WK, MB, JN, KM, VI, DI, AK); and the First Choice Community Health Care, Albuquerque (WK).

Funding: Development of the WellRx Toolkit was supported with a grant from the Blue Cross/Blue Shield Community Grant Program.

Conflict of interest: WK, JN, KM, VI, and DI are practicing physicians at clinics where the pilot was implemented. Each of them served as "participant-observers" of the process and recorded thoughts and notes for research according to an institutional review board-approved protocol.

Corresponding author: Will Kaufman, MD, MPH, Department of Family \& Community Medicine, University of New Mexico, 1 University of New Mexico, MSC09-5065, Albuquerque, NM 87131 (E-mail: wkaufman@salud.unm.edu).
Blind Side," 4 of every 5 primary care physicians (among 1000 surveyed) said that social needs are as important to address as medical conditions, that they do not feel confident in their ability to address those needs, and that by not addressing them, their patients' health suffers. ${ }^{2}$

The inability to take action on unmet social needs can be demoralizing for primary care providers who already feel overburdened by treating complex medical needs, complying with new documentation requirements, and confronting pressing time demands. Yet we know that patients, especially those from communities with high rates of poverty, experience significant nonmedical socioeconomic challenges that negatively affect their health. ${ }^{3,4}$ Primary care providers experience a sinking feeling when after the clinical encounter, their hand on the doorknob to leave the examination room, their patient adds 1 more 
reason for the visit-perhaps they lost their job, are unable to afford their medicine, or are about to be evicted from their home.

Screening for social needs has proven valuable for certain age groups: children during well-child visits, ${ }^{5}$ patients with chronic habits such as smoking, ${ }^{6}$ and high-risk patients with complex chronic diseases. ${ }^{7}$ The WellRx pilot cast a wider net, evaluating the feasibility of systematically screening for and addressing patients' social needs during every visit in busy general primary care settings.

\section{Methods}

Institutional review board approval was obtained to conduct a 90-day feasibility study with providers in 3 family medicine clinics in Albuquerque, New Mexico-2 run by a public university teaching hospital and 1 by a federally qualified community health center. Each of the clinics serves a large, low-income population. With funding from the Blue Cross/Blue Shield Community Grant program, researchers in the Office for Community Health at the University of New Mexico convened providers and community health workers (CHWs) from the 3 clinics to identify the domains of greatest social need experienced by the patients they serve. Eleven were identified: food insecurity, housing, utilities, income, employment, transportation, education, substance abuse, child care, safety, and abuse. The domains were incorporated into a pretested, 11-item questionnaire (available in English or Spanish). A literacy specialist from a university hospital ensured that the questions conformed to "low literacy" (Appendix). Our objectives were to obtain concrete data on the level of patient need, to test different methods of administering the screening tool, and to identify the best approach to connecting patients to needed resources and services.

An attempt was made to screen all patients, either by self-administered questionnaires distributed by front desk staff or by medical assistants (MAs) while recording vital signs. Sites that chose to have MAs administer the surveys were concerned that literacy issues would cause patients, especially those most in need, to decline to complete them. Patients' responses on hard-copy questionnaires were gathered and tabulated. Five members of the research team-1 family medicine faculty member (WK) and 4 family medicine resi- dents (KM, JN, VI, DI)-were providers at the participating clinic sites. As "participant-observers," they kept journals of their experience with implementing WellRx. Other members of the team (JP, MB) trained clinic staff, gathered data on operational experiences during implementation of WellRx, and documented the role of CHWs in this process. CHWs had extensive experience working in different capacities in their communities. They were trained by the Office for Community Health Workers in a 1-week intensive orientation that provided skills in working within the clinic system, including accessing electronic medical records. All received extensive training in accessing and connecting patients to community resources.

\section{Results}

WellRx questionnaires were completed by $3048 \mathrm{pa}-$ tients over the course of the 90-day pilot. MAs' faceto-face-administration of the questionnaire yielded the highest percentage of patients reporting adverse social determinants. A total of 2038 questionnaires were completed by the MAs and 1110 were completed by self-administration. Of those surveyed, $46 \%$ $(n=1413)$ reported at least 1 social need. Of those reporting a social need, 63\% $(\mathrm{n}=890)$ indicated multiple needs. Needs most often indicated concerned utilities, income, employment, and education (Figure 1). Previously unknown patient needs were identified and addressed. Patients who screened positive for unmet social needs were offered assistance in connecting with appropriate services and resources. MAs became resources to patients by handing out resource sheets to address identified social needs, resulting in a significant enhanced role for MAs. The role of MAs in identifying social problems and CHWs in intervention led providers to feel that their workloads had lightened, leading to a greater ease of practice and greater confidence that their patients were receiving quality care. In the clinic with $\mathrm{CHWs}$, patients reporting social needs were referred to a CHW. Services offered by CHWs included helping patients to access resources like food banks and to fill out job applications, accompanying patients to apply for food stamps, conducting home visits, or arranging family meetings with the health care team. A patient's level of need dictated the intensity and duration of the CHW's interaction with that patient-usually 1 contact a month and usually for $<3$ months. Using WellRx greatly accelerated the integration of CHWs 
Figure 1. Nonmedical needs identified during the WellRx pilot.

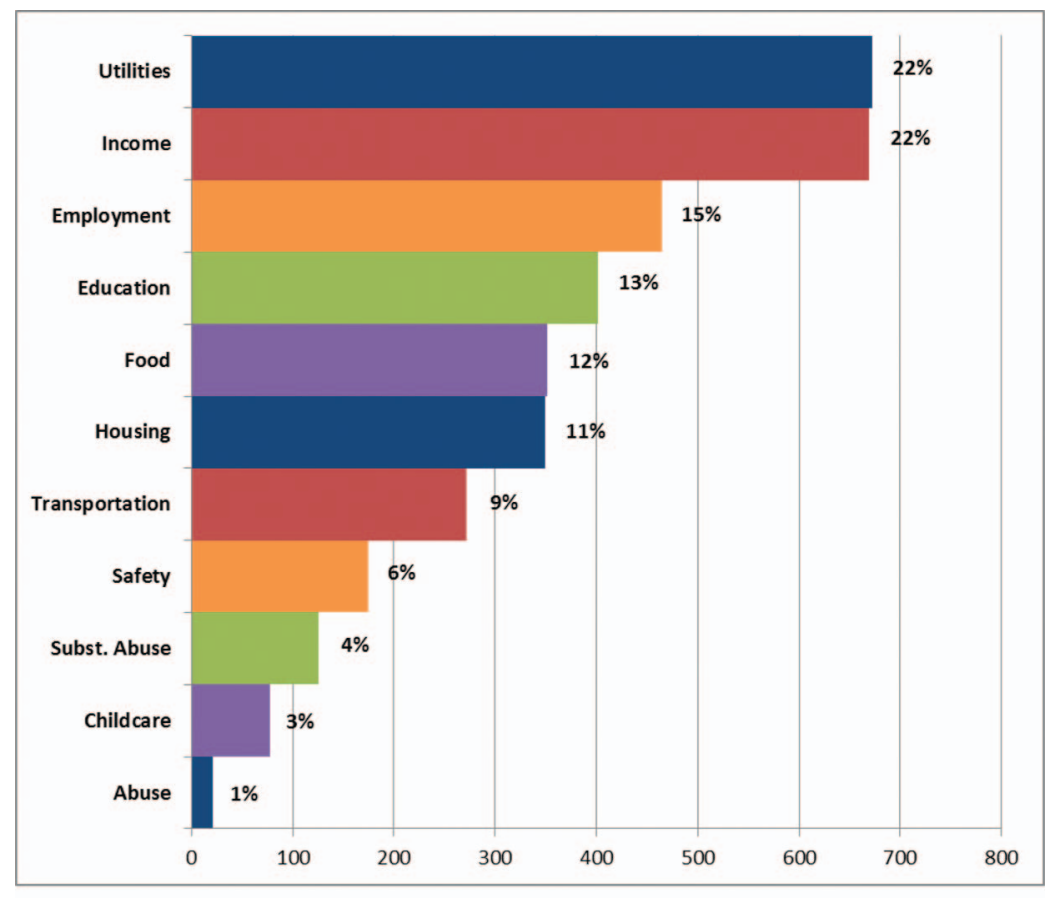

Number of patients who screened positive for at least one social need.

into primary care teams. None of the sites reported negative effects on efficiency created by use of the WellRx tool.

Feasibility of the pilot informed key policy decisions by the university teaching hospital, the state department of health, and 2 of the 4 managed care organizations that administer Medicaid programs in New Mexico. The university hospital has now institutionalized the WellRx by requiring that all patients in its 7 primary care clinics be screened for social needs and that those needs be addressed by CHWs newly hired for each clinic. All primary care residents now train at a site with this expanded model of care whereby social determinants are not only identified but also addressed.

\section{Discussion}

The WellRx Pilot revealed important insights for primary care practice.

\section{Concrete Documentation of Patient Needs}

The WellRx screening process produced concrete data about the magnitude of social needs in primary care patients' lives, resulting in better-informed clinic providers and staff, who are now able to develop more effective intervention and management plans.

\section{Effect of WellRx on Residents and Faculty}

WellRx provided an innovative vehicle for training. Residents learned practical skills for engaging patients in discussions that would not normally surface during clinic visits. ${ }^{8}$ Primary care physicians were initially skeptical about the value of the pilot to patient care, but residents who took part in the pilot became its strongest advocates, teaching attending physicians who were not participating in the pilot about the importance of screening for social needs. At 1 site, 7 providers who were not involved in the WellRx pilot were so impressed by what the residents had been teaching them that they decided to start using WellRx as their diabetes control quality improvement project, and they began referring appropriate patients in this select population to CHWs for action on social needs.

CHWs as Crucial Members of the Primary Care Team The WellRx pilot revealed the important role CHWs can play in a primary care clinic. The University of New Mexico Office for Commu- 
nity Health has many years of experience in training and deploying CHWs to help address the social needs of high-cost/high-risk patients enrolled in Medicaid managed care. ${ }^{9}$ But these CHWs have always worked in the community, with little linkage to the primary care clinics to which Medicaid enrollees are assigned. CHWs have key skills for helping patients navigate external bureaucracies; they provide assistance with complicated application processes and even accompany patients who lack the skills to do so on their own to apply for benefits. The CHWs complement and extend the reach of the clinic-based social worker through home visits and visits to community sites.

\section{WellRx as a Trigger for Broader Institutional Transformation}

Providers often believe that screening for patients' nonmedical social needs is not feasible in a clinic setting in terms of time and the ability to provide assistance. In addition, these needs are not generally considered to be within the purview of the medical system. The WellRx pilot demonstrated that it is feasible for a clinic to screen and address patients' social needs on site, without disrupting clinic flow and while actually improving provider ease of practice and enhancing staff roles. Because the WellRx pilot was incorporated into some of the busiest and most visible family medicine clinics within a university health system, word of its positive outcomes on clinic practice spread rapidly and influenced the university hospital administration to hire CHWs and incorporate the screening tool into all primary care clinics.

\section{Innovative Clinic Improvement Pilot Can Affect State Policy}

In March 2014 the governor of New Mexico signed into law the Community Health Workers Act, which paved the way for a certification process for CHWs in New Mexico and included the possibility of Medicaid reimbursement for certified CHW services. But few models existed in which CHWs were fully integrated into primary care practices. The success of the WellRx pilot laid the groundwork for a larger study involving a collaboration between state Medicaid managed care, the university, Molina Health Care of New Mexico, Blue Cross Blue Shield of New Mexico, and 2 federally qualified health centers-Hidalgo Medical Services and First Choice Community Healthcare. That study is evaluating screening for social needs and addressing those needs through CHWs integrated into primary care clinics by determining their impact on care quality and cost for 10,000 Medicaid enrollees, including both healthy and very ill patients.

The authors acknowledge the numerous individuals who assisted with implementation of the pilot, including physicians, residents, physician assistants, medical assistants, nurses, receptionists, clinic coordinators, and clinic directors at all the sites for participating in the project.

\section{References}

1. Schroeder SA. Shattuck Lecture. We can do betterimproving the health of the American people. New Eng J Med 2007;357:1221-8.

2. Health care's blind side: the overlooked connection between social needs and good health. Princeton (NJ): Robert Wood Johnson Foundation; 2011. Available from: http://www.rwjf.org/content/ dam/farm/reports/surveys_and_polls/2011/rwjf71795. Accessed March 17, 2016.

3. Marmot M. Social determinants of health inequalities. Lancet 2005;365:1099-104.

4. Krueger PM, Tran MK, Hummer RA, Chang VW. Mortality attributable to low levels of education in the United States. PLoS One 2015;10:e131809.

5. Garg A, Toy S, Tripodis Y, Silverstein M, Freeman E. Addressing social determinants of health at well child care visits: a cluster RCT. Pediatrics 2015;135: e296-304.

6. Lacey L, Tukes S, Manfredi C, Warnecke RB. Use of lay health educators for smoking cessation in a hard-to-reach urban community. J Community Health 1991;16:269-82.

7. Cantor JC, Chakravarty S, Tong J, Yedidia MJ, Lontok O, DeLia D. The New Jersey Medicaid ACO Demonstration Project: seeking opportunities for better are and lower costs among complex low-income patients. J Health Polit Policy Law 2014;39: $1185-211$.

8. McCalmont K, Norris J, Garzon A, et al. Community health workers and family medicine resident education: addressing the social determinants of health. Fam Med. 2016;48: 259-63.

9. Johnson D, Saavedra P, Sun E, et al. Community health workers and Medicaid managed care in New Mexico. J Community Health 2012;37: $563-71$. 


\section{Appendix}

WellRx Questionnaire

DOB Male Female

WellRx Questions

1. In the past 2 months, did you or others you live with eat smaller meals or skip meals because you didn't have money for food? Yes No

2. Are you homeless or worried that you might be in the future? Yes

3. Do you have trouble paying for your utilities (gas, electricity, phone)? Yes

\begin{tabular}{|c|}
\hline No \\
\hline No \\
\hline No \\
\hline No \\
\hline No \\
\hline No \\
\hline No \\
\hline No \\
\hline No \\
\hline No \\
\hline
\end{tabular}

4. Do you have trouble finding or paying for a ride? Yes

5. Do you need daycare, or better daycare, for your kids? Yes

6. Are you unemployed or without regular income? Yes

7. Do you need help finding a better job? Yes

8. Do you need help getting more education? Yes

9. Are you concerned about someone in your home using drugs or alcohol? Yes

10. Do you feel unsafe in your daily life? Yes

11. Is anyone in your home threatening or abusing you? Yes

The WellRx Toolkit was developed by Janet Page-Reeves, PhD, and Molly Bleecker, MA, at the Office for Community Health at the University of New Mexico in Albuquerque. Copyright (C) 2014 University of New Mexico. 